\title{
Assessing the Skills of Rossby Centre Regional Climate Model in Simulating Observed Rainfall over Rwanda
}

\author{
Janet Umuhoza ${ }^{1,2,3}$, Lin Chen ${ }^{1,2 *}$, Lucia Mumo ${ }^{1,2,4}$ \\ ${ }^{1}$ Key Laboratory of Meteorological Disaster, Ministry of Education (KLME)/Joint International Research Laboratory of Climate \\ and Environmental Change (ILCEC)/Collaborative Innovation Center on Forecast and Evaluation of Meteorological Disasters \\ (CIC-FEMD), Nanjing University of Information Science and Technology, Nanjing, China \\ ${ }^{2}$ College of Atmospheric Science, Nanjing University of Information Science and Technology, Nanjing, China \\ ${ }^{3}$ Rwanda Meteorology Agency, Kigali, Rwanda \\ ${ }^{4}$ South Eastern Kenya University, Kitui, Kenya \\ Email: *chenlin@nuist.edu.cn
}

How to cite this paper: Umuhoza, J., Chen, L. and Mumo, L. (2021) Assessing the Skills of Rossby Centre Regional Climate Model in Simulating Observed Rainfall over Rwanda. Atmospheric and Climate Sciences, 11, 398-418.

https://doi.org/10.4236/acs.2021.113023

Received: March 31, 2021

Accepted: May 28, 2021

Published: May 31, 2021

Copyright (c) 2021 by author(s) and Scientific Research Publishing Inc. This work is licensed under the Creative Commons Attribution International License (CC BY 4.0).

http://creativecommons.org/licenses/by/4.0/

(c) (i) Open Access

\begin{abstract}
Rainfall over Rwanda is highly variable both in space and time. This variability leads to chronic food insecurity due to the overdependence of the economy on rain-fed agriculture systems. This study aims to evaluate the skills of Rossby Centre Regional Climate Model (RCA4) simulations driven by 10 GCMs for the period 1951-2005 using the Global Precipitation Climatology Centre (GPCC v8) as a reference. Different statistical and geospatial metrics were used to deduce the model's skills in simulating seasonal and annual rainfall. Results show that the country received bimodal rainfall pattern; March-May (MAM) and September-December (SOND). The RCA4 models are inconsistent in simulating the MAM rainy peak. However, the models are coherent in simulating SOND seasonal peak despite exhibiting wet bias. The models show reasonable skills in simulating mean annual cycle than interannual variability as depicted by insignificant correlation and different signs of rainfall trend. Conclusively, the performance of RCA4 models in simulating observed rainfall characteristics over Rwanda is relatively weak. The performance of the models differs at various time scales. Nevertheless, the models can be ranked from the best performing to the least as; CSIRO, CanESM2, CNRM, GFDL, MIROC5, ENS, EC-Earth, HadGEM2, IPSL, MPI, and NorESM1. Ranking the performance of RCA4 historical models acts as a basis for future climate model's selection depending on the purpose of the study. The findings of this study may help in devising appropriate climate adaptation measures to respond to the ongoing global warming for sustainable eco-
\end{abstract}


nomic and livelihood development. Additionally, modelers may improve the model's parametrization schemes and lessen the inherent chronic biases for a better presentation of the future.

\section{Keywords}

CORDEX, RCA4, Rainfall, Rwanda, Simulation Bias

\section{Introduction}

Understanding the current and future rainfall trends, and its variability over Rwanda is paramount. The footprints of climate change and variability are evidenced over the region due to increased occurrence of extreme climate events [1] [2] [3]. Rainfed agriculture is the core of the economy hence rainfall variability has detrimental impacts on the socioeconomic of the country [4]. Unfortunately, the main crop growing seasonal rainfall has been decreasing over the country [5] [6] [7] [8] [9], hence threatening food security and livelihood.

Food insecurity and clashes over natural resources have been witnessed over East Africa region due to limited resources. Increased frequency and intensity of occurrences of droughts and floods [10] [11] have exacerbated food insecurity in the already vulnerable zone due to weak adaptive capacity. Prevalence of pests and diseases due to climate change like the recent invasion of desert locust over the East Africa region has threatened many people's livelihood and the economy at large. The numerical model has become an effective tool to understand the climate change and predict the climate at different time scales. Therefore, gauging the skills of the current RCA4 historical models is crucial in selecting the best performing model that can be used for future climate projections and impacts studies.

Around the globe, the General Circulation Models (GCMs) have been widely used to understand the climate issues [12] [13] [14] [15]. In some regions, the models are skillful like the subtropics [16] [17] while in other regions especially over the tropics, the models show relatively poor skills and huge models' divergence [13] [15] [18]. This discrepancy in the performance of GCMs has been partly linked to the imperfect parametrization schemes, such as the convective schemes in the GCMS [19]. For one thing, the parameterization schemes may be sensitive to regions, that is, an appropriate scheme for a region may not fit for another region. As the model performance varies for different regions, one of the purposes of this study is to examine the performance in simulating the regional climate in East Africa.

Under the umbrella of the World Climate Research Program (WCRP), CMIP modeling groups have been developing models for the last 20 years [20]. These models have been on improvement in both physical parametrization and horizontal resolution, e.g., most of the CMIP3 atmospheric model has a horizontal 
resolution of $300 \mathrm{~km}$ while most of CMIP5 models have a resolution of around $200 \mathrm{~km}$ [21]. Encouragingly, improved performance across CMIP models' generations have been observed by [22] in simulating observed rainfall over East Africa (EA) when comparing the CMIP3 with CMIP5. The study documented that, CMIP3 was less skillful in simulating the short-term rainfall peak in April but such bias was rectified in CMIP5 that depicted satisfactory skills in capturing the seasonal peak.

The course (low-medium) resolution of GCMs has hindered them from capturing mesoscale features that control rainfall patterns in many parts of the globe [23] [24]. Models with high resolution are anticipated to be capable of simulating skillfully convective mesospheric features and multiple-scale interaction than GCMs with coarse resolution [25] [26]. Due to the limitation of the computing resource and the difficulty in model designing, high-resolution simulation and prediction for a global region is still in its infancy. This promoted the scientists around the globe to widely deploy both dynamical and statistical downscaling techniques to improve on the model's simulation ability. Despite the advantages brought by downscaling methods, the physics uncertainty derived from the driving GCMs can lead to more uncertainty in the regional climate model (RCMs), which yields the biased results [27] [28].

Remarkably, previous studies that evaluated the skills of CORDEX (Coordinated Regional Downscaling Experiment) historical models consensually agree that RCMs still exhibits inadequate skills to simulate rationally rainfall characteristics over different regions [29] [24] [18]. This can be linked to the fact that the majority of these studies evaluated the first phase of CORDEX models that were driven by ERA-Interim reanalysis data [30] [31]. The systematic errors in simulating the large-scale circulation features will greatly influence the skills of the RCMs in replicating the climate characteristics. This calls for the need to evaluate the skills of the second phase of CORDEX models that are driven by CMIP5 [21], as few attentions has been paid for this aspect.

The main objective of this current study is to evaluate the performance of 10 CORDEX historical Climate models against observed rainfall. The findings of this study are vital for model developers, government policy makers and contribute significantly to the body of growing literature review on the performance of models in simulating observed climate. The remaining part of this paper will address the characteristics of the study domain, the types of datasets and methodology deployed in Section 2. Section 3 will present the findings and discussion at length. Conclusion and recommendations will be drawn in the last Section 4 .

\section{Study Domain, Data, and Methodology}

\subsection{Characteristics of the Study Area}

Rwanda is a tropical country located on Latitude $1.4^{\circ} \mathrm{S}$ to $2.51^{\circ} \mathrm{S}$ and Longitude $28.53^{\circ} \mathrm{E}$ to $30.53^{\circ} \mathrm{E}$ with an area of approximately $26,338 \mathrm{~km}^{2}$ (Figure 1). The 


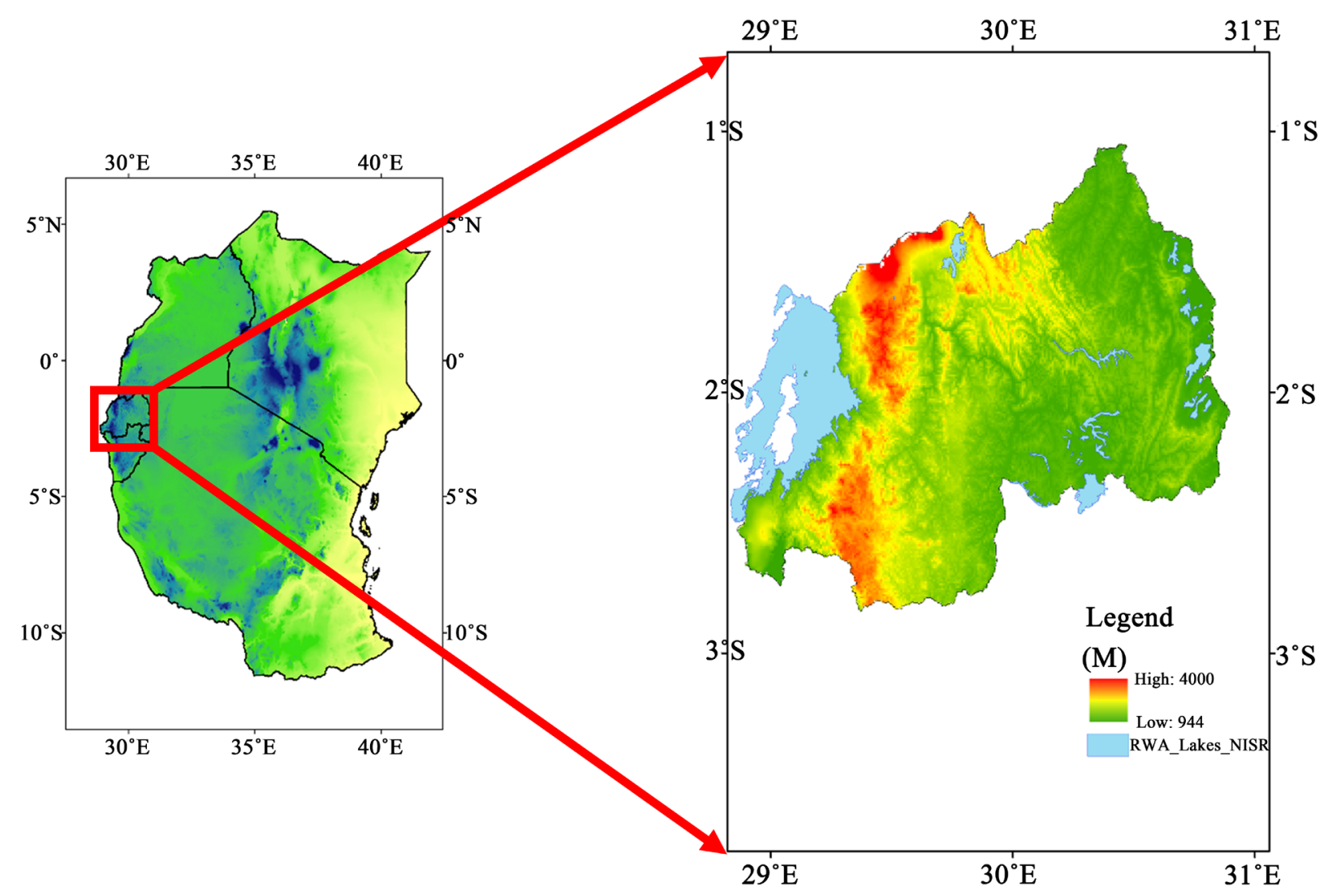

Figure 1. The insert shows a map of East Africa on the left (a) while the map of Rwanda is on the right (b). The background color shows the elevation (meters).

country experienced dipole rainfall regimes, i.e., March-May (MAM) and September to December (SOND); and two dry seasons, i.e., June-August (JJA) and January-February (JF) on its annual cycle [5] [7] [32] [33]. These rainy seasons are known locally as "long-term rainy seasons" that refers to the MAM season and "short-term rainy season" that refers to the SOND season. Such termination is based on the amount of rainfall during the rainy season. Throughout the remainder of this study, MAM and SOND will be used to refer to these two seasons.

Rainfall is highly erratic and unevenly distributed within Rwanda during both rainy seasons despite the country's location is along the equatorial zone. The country exhibits complex mountainous topography ranging from 900 to $4507 \mathrm{~m}$ [5]. High altitude regions like the Virunga volcanic chains and Congo-Nile ridges are located on the northwestern part of the country with a height of $1800-4500$ $\mathrm{m}$. Those regions receive the largest amount of rainfall with an annual amount ranging from $1300 \mathrm{~mm}$ to $1550 \mathrm{~mm}$ [32]. The low-lying land lies on the eastern parts of the country. This complex topographic feature highly influences the climate characteristics of the country.

The seasonality of the rainy seasons is modulated by the equatorial rain belt over the region [34] [35]. MAM rainfall season is controlled by mesospheric features like topography and Lakes while SOND rains are controlled by large- 
scale features like El Niño Southern Oscillation (ENSO), Indian Ocean Dipole (IOD), subtropical Anticyclones [36]-[42]. Remarkably, the convergence of anticyclones, i.e., Mascarene High at Madagascar coast and feeds to the Mozambique coast and St. Helena high conveyed from the South Atlantic Ocean to Congo basin then to Lake Kivu, leads to an anomalous amount of rainfall during MAM season [32]. The dry seasons are caused by cold and dry air masses from the Arabian Sea that forms the Siberian anticyclone [5] [37].

\subsection{Data}

Several datasets were deployed in this study from 1951-2005. Monthly precipitation data obtained in form of "Precipitation flux" $\left(\mathrm{kg} / \mathrm{m}^{2} / \mathrm{s}\right)$ for 10 RCA4 models in Coordinated Regional Climate Downscaling Experiment (CORDEX) was be used. These models are an advancement of the High-Resolution Limited Area Model (HIRLAM) [43], in which the improved dynamical and physical parametrization were applied [44]. This dataset has been developed by the Swedish Meteorological and Hydrological Institute [45] and archived at https://www.smhi.se/en/research/research-departments/climate-research-rossby-c entre2-552. The information for the RCA4 models used are illustrated in Table 1. Based on the location of the study domain, we used the RCA4_AFRICA (AFR44) domain with a resolution of $50 \mathrm{~km}$ (approx. $0.44^{\circ}$ ). The Digital Elevation Model data was obtained from National Oceanic and Atmospheric Administration archived on https://www.ngdc.noaa.gov/mgg/topo/topo.html.

As the densely populated synoptic stations remain a major challenge over Africa [39], the precipitation data derived from the Global Precipitation Climatology Centre (GPCC) version 8 was used in this study. The available station data were used to validate GPCC dataset which was used in the subsequent analysis

Table 1. The description of the CMIP5 climate models that were downscaled by the RCA4 group to RCA4, v1.

\begin{tabular}{|c|c|c|c|}
\hline Modelling Institution & Horizontal Resolution & Model full name & Acronym \\
\hline $\begin{array}{l}\text { Canadian Centre for Climate Modelling and Analysis, Environment and Climate } \\
\text { Change Canada, Victoria, BC V8P 5C2, Canada }\end{array}$ & $2.8^{\circ} \times 2.8^{\circ}$ & CanESM2 & CanESM2 \\
\hline Centre national de recherches météorologiques (France) & $1.4^{\circ} \times 1.4^{\circ}$ & CNRM-CM5 & CNRM \\
\hline Commonwealth scientific and industrial research organization & $1.875^{\circ} \times 1.875^{\circ}$ & CSIRO-MK3-6-0 & CSIRO \\
\hline EC-Earth-Consortium & $1.125^{\circ} \times 1.125^{\circ}$ & EC-Earth3 & EC-Earth \\
\hline NOAA geophysical fluid dynamics laboratory, USA & $2.5^{\circ} \times \sim 2.0^{\circ}$ & GFDL-ESM2M & GFDL \\
\hline Met Office Hadley Centre & $1.25^{\circ} \times 1.9^{\circ}$ & HadGEM2-ES & HadGEM \\
\hline Institute Pierre-Simon Laplace, France & $2.5^{\circ} \times \sim 1.27^{\circ}$ & IPSL-CM5A-MR & IPSL \\
\hline $\begin{array}{l}\text { Japan Agency for Marine-Earth Science and Technology (AMSTEC), } \\
\text { Atmosphere and Ocean Research Institute, The University of Tokyo, National } \\
\text { Institute for Environmental Studies, and R-CCS (RIKEN Center for } \\
\text { Computational Science, Hyogo 650-0047, Japan }\end{array}$ & $1.4^{\circ} \times 1.4^{\circ}$ & MIROC5 & MIROC5 \\
\hline Max Planck institute for meteorology (Germany) & $1.875^{\circ} \times 1.875^{\circ}$ & MPI-ESM-LR & MPI \\
\hline Norway Climate modeling Consortium & $1.875^{\circ} \times 2.5^{\circ}$ & NorESM1-M & NorESM1 \\
\hline
\end{tabular}


as the reference dataset. For consistency purposes and fair comparison, both the observational data and the RCA4 model datasets were regridded to a common resolution of $0.44^{\circ} * 0.44^{\circ}$ using bilinear interpolation method.

\subsection{Methodology}

This study deployed various scalar statistical metrics to discern the skills of RCA4 models in simulating the observed rainfall characteristics over Rwanda. To obtain the multi-model ensemble mean, equal weight was assigned to each model. This method of building the model ensemble mean was adopted from [46]. Other statistical methods include: Standard deviation, Mean, Pearson Correlation coefficient, Relative percentage bias, Mann-Kendall trend test, and Sen's slope estimator. These methods can be elucidated mathematically as;

$$
\operatorname{Mean}(\mu)=\frac{\sum_{i=1}^{n}\left|X_{i}-\mu\right|}{n}
$$

After obtaining the means of the two datasets, it was essential to get the mean difference between the two using Root mean square error ( $R M S E)$. The value of the RMSE is taken as an absolute value. Remarkably, for a fair comparison of the model performance, is to scale the value of $R M S E$ either by the observed mean or the standard deviation. In this study observed mean $\left(\mu_{O B S}\right)$ was used (Equation (3))

$$
\begin{gathered}
R M S E=\frac{\sqrt{\frac{1}{n-1} \sum_{i=n}^{n}\left(x_{i}-\mu\right)^{2}}}{n} \\
n R M S E=\frac{R M S E}{\mu_{O B S}} \\
\text { Standard deviation }(\delta)=\sqrt{\frac{1}{n-1} \sum_{i=n}^{n}\left(x_{i}-\mu\right)^{2}}
\end{gathered}
$$

To understand the temporal agreement between the simulated rainfall and observation, the Pearson correlation method was used. The coefficient value is obtained by dividing the covariance between the observed and simulated model with the product of their standard deviation as expressed in (Equation (5)). The significance of the correlation value was tested using a t-test at a $95 \%$ confidence level.

$$
C C_{x y}=\frac{\sum_{i=1}^{n}\left(\text { Obs }_{i}-\mu_{\text {Obs }}\right) *\left(\text { Model }_{i}-\mu_{\text {Model }}\right)}{\sqrt{\sum_{i=1}^{n}\left(\text { Obs }_{i}-\mu_{\text {Obs }}\right)^{2} * \sum_{i=1}^{n}\left(\text { Model }_{i}-\mu_{\text {Model }}\right)^{2}}}
$$

Understanding the rainfall trend is important for agriculture purposes and water management. Non-parametric trend detection Modified Mann-Kendall test [47] [48] was used to assess the direction of the trend. The magnitude of the trend was assessed using a non-parametric Theil Sen slope estimator [49]. Non-parametric methods are more robust than their coequal parametric methods since they are not influenced by occurrences of extremes and outliers in 
the datasets [50]. More details of the methods can be found in [51] [52] [53] [54].

To understand the discrepancy between the observed and simulated mean values, relative bias is used. The relative bias of different models is scaled against the mean observation to unify them for a fair comparison of individual models. The Percentage Relative Bias (P.R.B) can be elucidated mathematically as;

$$
\text { P.R.B }=\frac{\sum_{i=1}^{n} \text { Model }_{p}-\text { Obs }_{p}}{\sum_{i=1}^{n} \mathrm{Obs}_{p}} * 100 \%
$$

Taylor diagram [55] was used to assess spatially the performance of the models when statistical measures like standard deviation, correlation, and centered-root mean square error (RMSE) are combined. If the model is near to the reference data (Observation), the model is considered to exhibit reasonable skills in simulating the observation. Additionally, if the models are spread apart from each other, it depicts divergence of the models/lack of consensus in their prediction ability and the opposite is true.

Lastly, we combined these statistical methods using skill scores [56]. The skills of the models at both seasonal and annual scales were subjected to an absolute error to capture their magnitude of deviation from the observation or the ideal values i.e. 1 in the case of the correlation coefficient. Then, we added up the Skill score values (SSV) at all the time scale considered. The smaller the $S S V$, the better the performance of the models and vice versa is true. The following scalar metrics were used to build the $S S V$; Normalized Root means square error (nRMSE), Correlation coefficient (CC), absolute relative errors for; relative bias and, Theil-slope estimator (TSA). The $S S V$ can be illustrated mathematically as;

$$
S S V=(1-C C)+n R M S E+|R \cdot P . B|+|T S A|
$$

\section{Results and Discussion}

\subsection{Mean Annual Cycle Characteristics}

As described in Sect. 2, the mean rainfall in Rwanda exhibits bimodal rainfall patterns, MAM rainy season and SOND rainy season. Virtually, the skills of the model to simulate the seasonality of rainfall over Rwanda lies primarily in the model's ability to capture the north-south movement of ITCZ, which is an essential baseline of model's basic performance. Therefore, we firstly investigate whether the RCA4 models have the ability of duplicating the seasonality of the mean rainfall.

As clearly seen in Figure 2, the mean rainfall simulated by all the models exhibit a semi-annual feature, indicating that all the models can capture the annual cycle of rainfall over Rwanda. Here the GPCC dataset was also evaluated, in order to be used as the reference dataset in the subsequent analysis. In general, the annual cycle of rainfall derived from the GPCC (thick red curve in Figure 2) matches well with the observation (thick blue curve in Figure 2), in terms of both the temporal evolution feature and the magnitude. Specifically, the correlation 


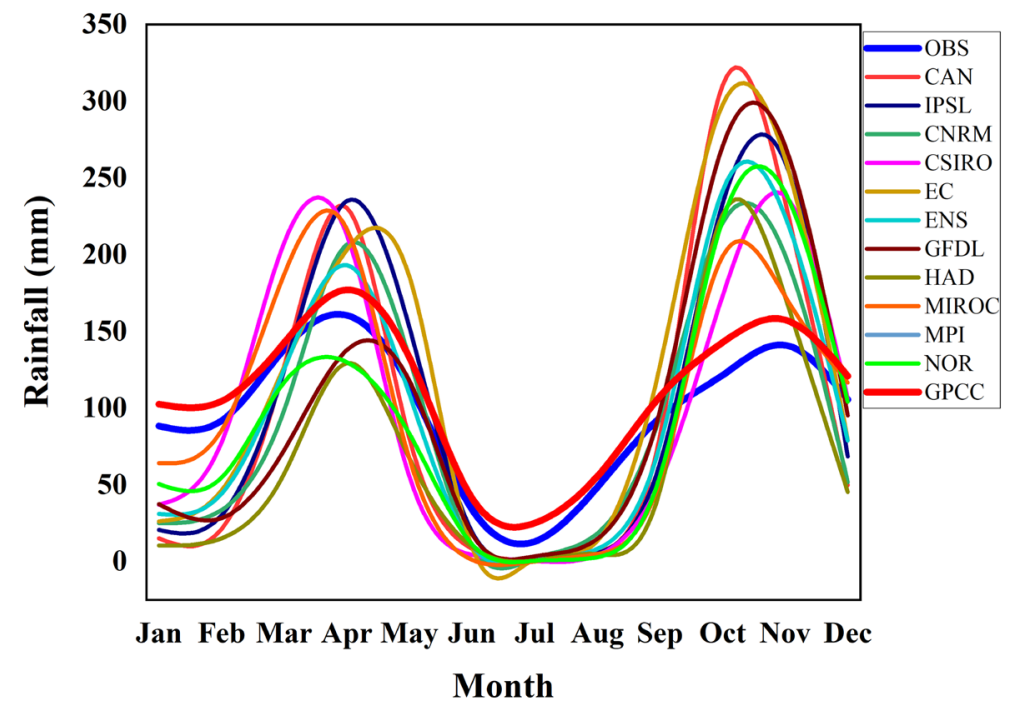

Figure 2. The skills of RCA4 models in simulating the mean annual rainfall cycle (mm/month) over Rwanda from 1951-2005.

coefficient between them reaches more than 0.9 , indicating that the GPCC captures the seasonality feature excellently. Therefore, the GPCC data is used as a potential reference in the subsequent analysis.

To assess the ability of RCA4 models in simulating the annual cycle of rainfall in detail, we further examine the dynamical aspects of the annual cycle of rainfall, including the onset, peak, and cessation of rainfall. In general, the RCA4 models can simulate the MAM seasonal rainfall peak, despite showing some biases in the magnitude (Figure 2). Specifically, the MAM seasonal rainfall is underestimated by three models (HadGEM2, NorESM1 and GFDL-ESM2M) while the rest of the models overestimated the seasonal rainfall. In contrast, all the RCA4 models exhibit wet bias when simulating the SOND seasonal rainfall, compared to the observation data and GPCC (Figure 2). The higher values of precipitations given by the models may indicate that the parametrization concern an accumulation effect.

We further assess the RCA4 model performance in simulating the observed mean annual cycle, in terms of three aspects (i.e., correlation, root mean square, and standard deviation). As summarized in Figure 3, the models show reasonable skills and consistency in simulating the mean annual cycle with low spatial variability and normalized RMSE of less than one. In this case, the best performing model is CSIRO while the least performing its MIROC5. These findings are consistent with previous studies that also focused on this region and identified CSIRO has the best performance in simulating the mean annual cycle [57] [15].

\subsection{Spatial Distribution of Seasonal Rainfall over Rwanda}

Observed spatial patterns depicts that most parts of the country are wet during the MAM rainy season, as shown in Figure 4(a). The regions surrounding Lake 


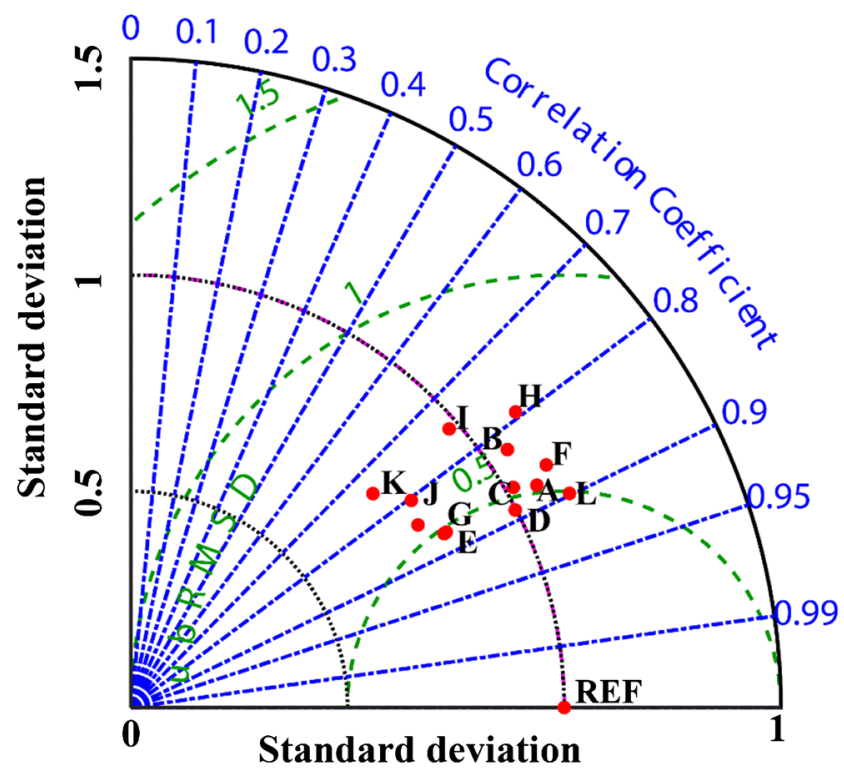

Figure 3. Summarizing multiple facets of RCA4 climate models in simulating observed mean annual cycle. The alphabetical letters denote; A-CanESM2, B-IPSL, C-CNRM, D-CSIRO, E-EC-Earth, F-Ensemble model, G-GFDL-ESM2M, H-HadGEM2, I-MIROC5, J-MPI, K-NorESM1.

(a)

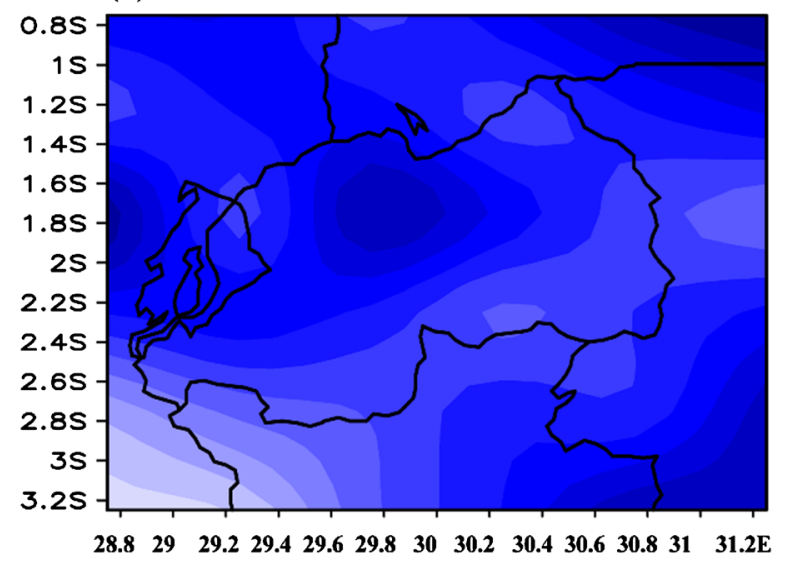

(b)

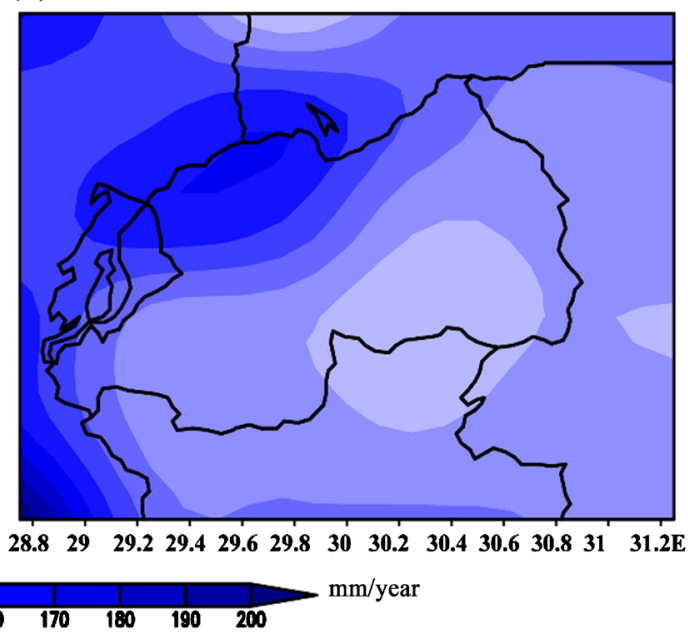

(c)
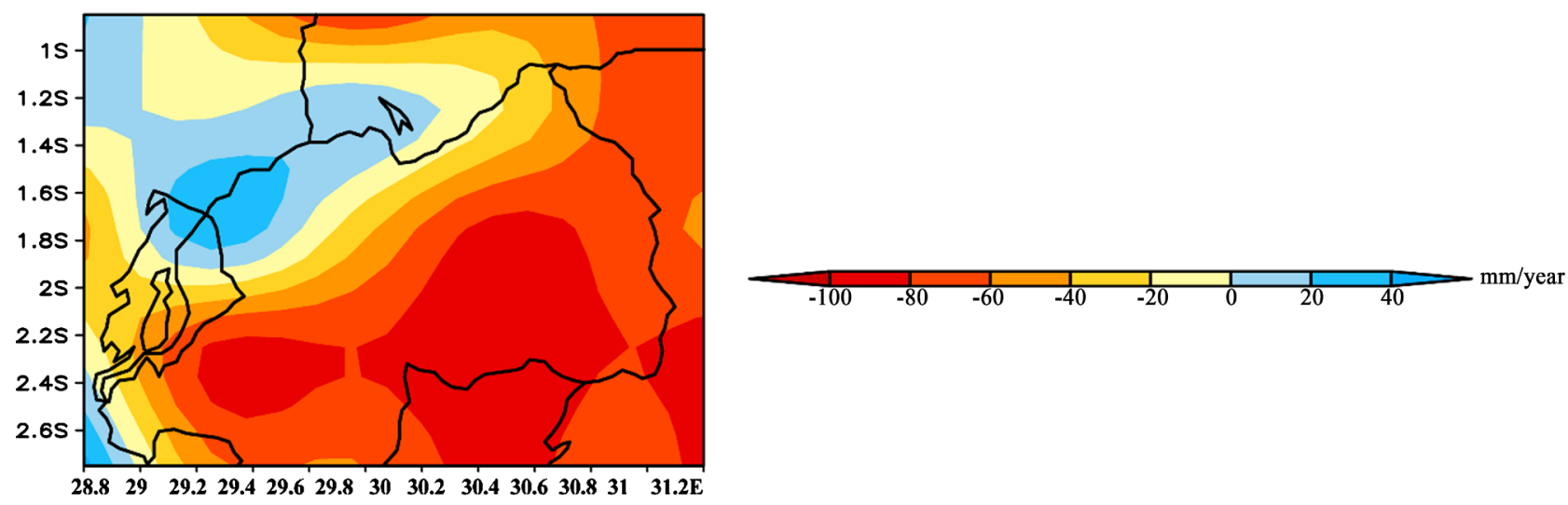

Figure 4. Spatial distribution of observed MAM seasonal rainfall (a), RCA4 models (b), and bias (c) in mm/year. 
Kivu and northwestern part of Rwanda receive the highest amount of rainfall during this season as compared to the other parts. Notably, the eastern parts are found to be drier than the rest of the country (Figure 4(a)). The MME made by the RCA4 models show reasonable skills in simulating this spatial distribution (Figure 4(b)). However, the models underestimate the rainfall amount in most parts of the country, especially for the southeastern region where the underestimation reaches around $100 \mathrm{~mm}$ /year. In the western parts, the models slightly overestimated the observed seasonal rainfall by $30 \mathrm{~mm} /$ year (Figure 4 (c)).

During SOND rainy season, the observed data shows that the country receives more rainfall than that during MAM. The spatial pattern remains relatively the same during the two seasons with the western regions wetter than the eastern side (Figure 5(a)). The MME result made by RCA4 models show relatively low skills in simulating the spatial pattern by documenting a high amount of rainfall on the northern parts of Lake Kivu as compared to the observation (Figure 5(b)). Succinctly, the RCA4 climate models show wet bias in simulating SOND seasonal rainfall over the northern parts of Rwanda while dry bias in the southern region (Figure 5(c)).

(a)

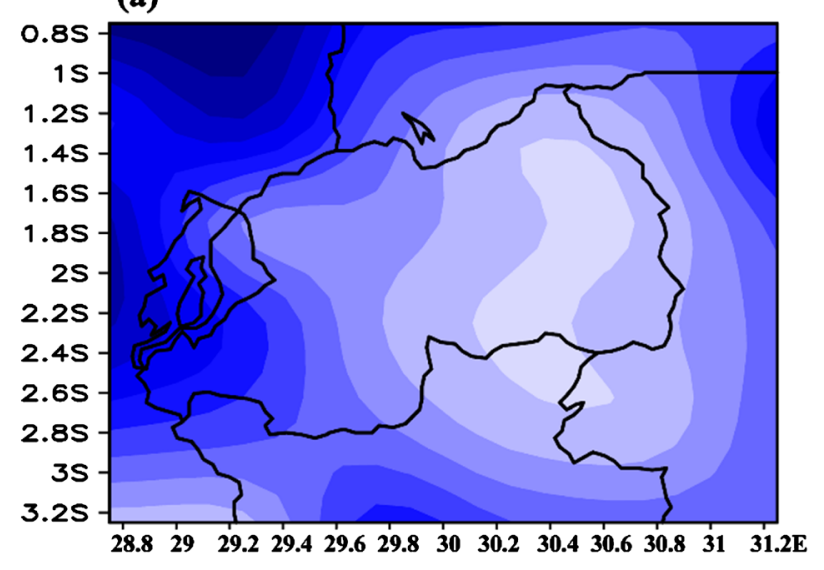

(b)

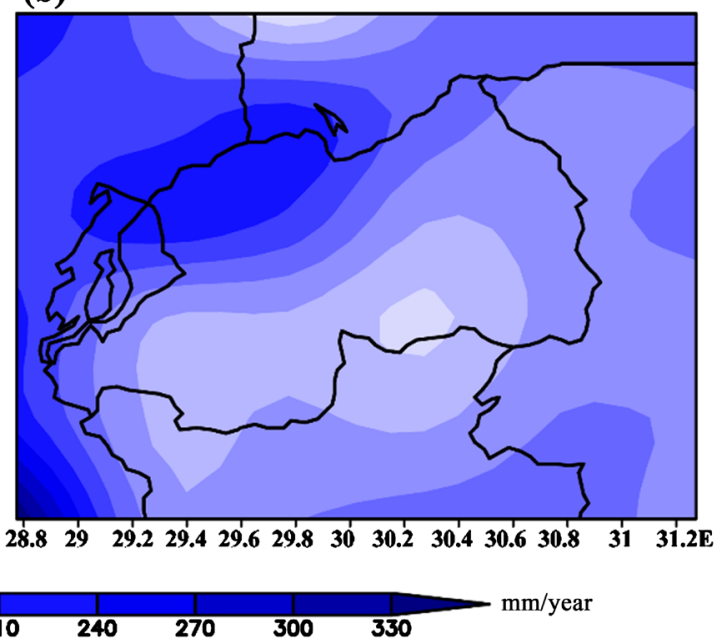

(c)

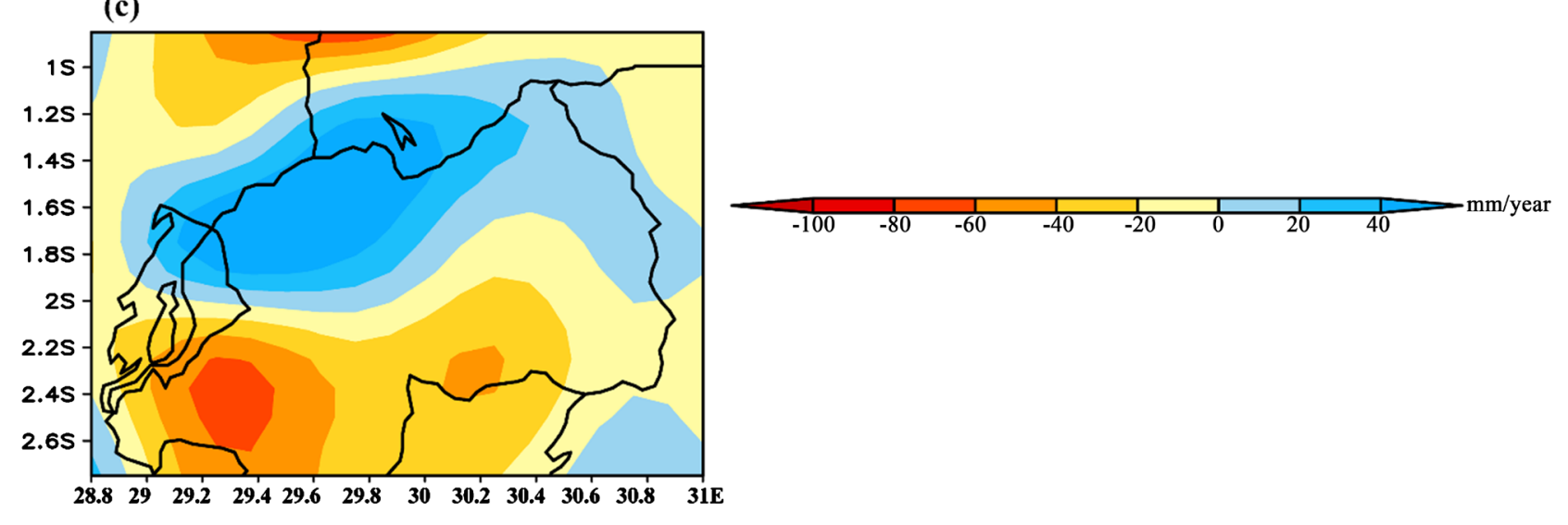

Figure 5. Spatial distribution of observed SOND seasonal rainfall (a), RCA4 models (b), and bias (c) in mm/year. 
The biases of the mean precipitation distribution may be linked to the orography. In Rwanda, the precipitation distribution exhibits more rainfall in the western parts, which is closely associated with the fact that the anomalous influx of moisture from Lake Kivu and the Congo airmasses is usually the source of the precipitation in Rwanda. As shown in Figure 1(b), the altitude sharply increases in the western edge of Rwanda and can reach around 4000 meters. Such a sophisticated orography may be beyond the simulation skill in the models and induce the bias in simulating the mean precipitation in Rwanda. It is worth mentioning that the orographic effects have been noted to significantly influence the skills of RCA4 models in simulating observed rainfall over Africa [18] [24]. Conclusively, RCA4 models have the ability in simulating the mean precipitation in MAM and SOND rainy seasons, but still show some biases in their spatial distribution.

\subsection{Seasonal MAM Rains Temporal Characteristics}

Table 2 shows the ability of the RCA4 climate models in simulating observed MAM seasonal rainfall statistics. Most of the models exhibit dry bias except CSIRO, EC-Earth, IPSL, and MPI that have a wet bias. The ability of the climate models to capture the temporal variability was low as portrayed by the majority of the models exhibiting insignificant negative correlation values. Few models that depicted positive relationships were CanESM2, CNRM, and NorESM1. Notably, none of the models exhibited an insignificant relationship with the observed MAM seasonal rainfall at a $95 \%$ significant level.

In the observation, the rainfall exhibits a decreasing trend at a rate of 0.10 $\mathrm{mm}$ /year for the MAM rainy season. Unfortunately, only two out of ten models (CNRM and IPSL) were able to capture such decreasing trend. This conforms to

Table 2. Skills of RCA4 models in simulating MAM seasonal rainfall (mm/year) mean statistics.

\begin{tabular}{ccccccc}
\hline Model & Mean & \%Bias & Stdev & RMSE & MK & TSA \\
\hline OBS & $\mathbf{1 5 0 . 8 9}$ & & $\mathbf{1 7 . 2 9}$ & - & $-\mathbf{0 . 1 0}$ & $-\mathbf{0 . 1 7}$ \\
CanESM2 & 145.97 & -3.26 & 30.14 & 0.23 & 0.05 & 0.14 \\
CNRM & 145.99 & -3.25 & 31.90 & 0.24 & -0.06 & -0.22 \\
CSIRO & 158.78 & 5.23 & 32.15 & 0.26 & 0.01 & 0.03 \\
EC-Earth & 171.85 & 13.89 & 34.10 & 0.31 & 0.06 & 0.20 \\
ENS & 142.49 & -5.57 & 8.46 & 0.15 & 0.24 & 0.21 \\
GFDL & 109.38 & -27.51 & 28.28 & 0.35 & 0.07 & 0.17 \\
HadGEM2 & 84.58 & -43.95 & 22.65 & 0.48 & 0.03 & 0.07 \\
IPSL & 170.74 & 13.15 & 27.15 & 0.27 & -0.07 & -0.21 \\
MIROC5 & 156.98 & 4.04 & 31.49 & 0.24 & 0.21 & 0.60 \\
MPI & 170.61 & 13.07 & 35.28 & 0.31 & 0.24 & 0.70 \\
NorESM1 & 110.05 & -27.07 & 26.94 & 0.34 & 0.17 & 0.42 \\
\hline
\end{tabular}


the "East Africa Climate paradox" where the observation shows decreasing rainfall trends while the GCMs show positive trends [58].

To summarize pictorially different aspects of the RCA4 models in simulating the observed MAM seasonal rainfall, the Taylor diagram was used (Figure 6). All the RCA4 models have some biases in simulating the mean rainfall in MAM season to various extent, and the MME results outperforms the individual model in simulating the observed MAM rain characteristics. This has been observed in the previous studies over the great horn of Africa that gauged the skills of RCA4 models against observations [18] [59].

\subsection{SOND Rainfall Characteristics}

The ability of the RCA4 models to simulate the observed SOND rains was also gauged. As shown in Table 3, the results show that all the models as well as the MME have shown wet bias in terms of the mean SOND rainfall, showing an overestimation of mean SOND rainfall to various extent. In terms of the interannual variation, the models exhibit high standard deviation than the observation (Table 3). In terms of long-term trend of SOND mean rainfall, the observation shows an insignificantly increasing trend at a rate of $0.03 \mathrm{~mm} /$ year during this period. Interestingly, only three RCA4 models (HadGEM2, IPSL, and MIROC5) were able to capture this increasing trend.

Diagrammatically, the three aspects of the RCA4 models' skills in simulating the observed SOND rainfall are shown in Figure 7. All the RCA4 models have some biases in simulating the mean rainfall in MAM season to various extent, but the MME results outperforms the individual model in terms of simulating

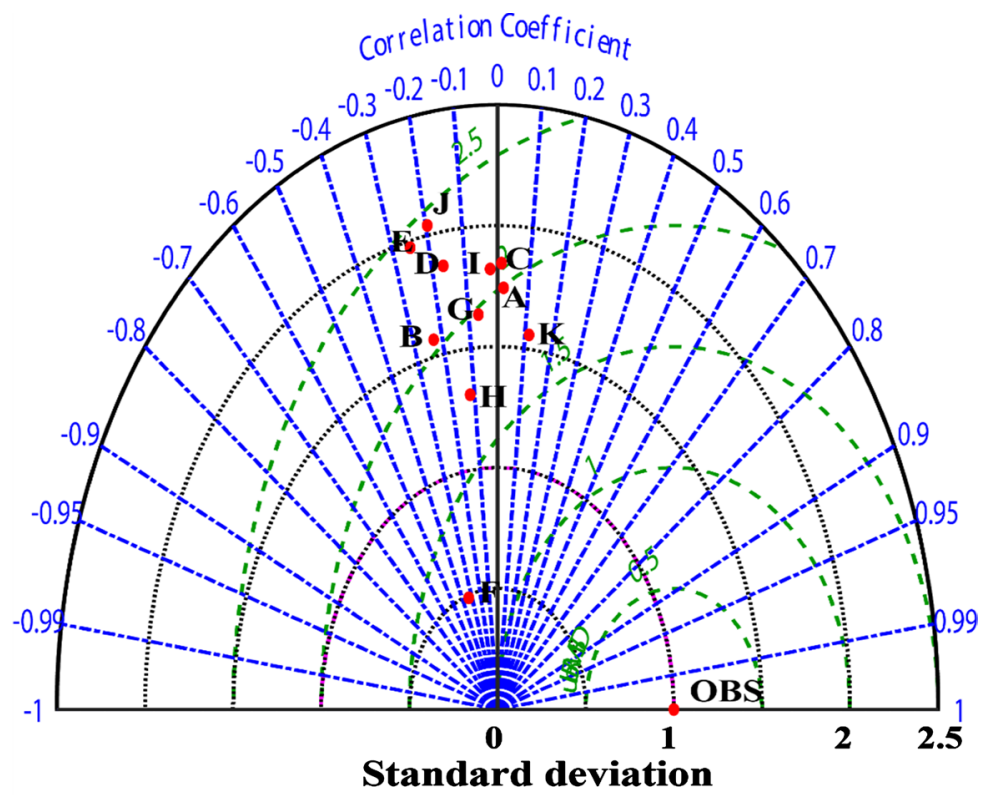

Figure 6. Taylor diagram depicting the performance of RCA4 model in simulating MAM seasonal rainfall mean statistics. The alphabetical letters denote; A-CanESM2, B-IPSL, C-CNRM, D-CSIRO, E-EC-Earth, F-Ensemble model, G-GFDL-ESM2M, H-HadGEM2, I-MIROC5, J-MPI, K-NorESM1. 
Table 3. RCA4 Skills in simulating mean SOND rainfall (mm/year) over Rwanda.

\begin{tabular}{ccccccc}
\hline Model & Mean & \%Bias & Stdev & RMSE & MK & TSA \\
\hline OBS & 132.20 & & 20.72 & & 0.03 & 0.07 \\
CanESM2 & 169.12 & 27.92 & 27.62 & 0.39 & -0.01 & -0.03 \\
IPSL & 156.61 & 18.46 & 24.68 & 0.30 & 0.08 & 0.18 \\
CNRM & 141.74 & 7.21 & 23.41 & 0.25 & -0.07 & -0.17 \\
CSIRO & 142.35 & 7.67 & 27.46 & 0.25 & -0.05 & -0.15 \\
EC-Earth & 191.76 & 45.05 & 28.23 & 0.51 & -0.08 & -0.26 \\
ENS & 155.39 & 17.54 & 8.71 & 0.24 & -0.05 & -0.05 \\
GFDL & 183.81 & 39.03 & 32.83 & 0.51 & -0.02 & -0.07 \\
HadGEM2 & 162.53 & 23.32 & 23.26 & 0.24 & 0.08 & 0.14 \\
MIROC5 & 135.40 & 2.41 & 22.34 & 0.21 & 0.09 & 0.20 \\
MPI & 154.83 & 17.11 & 28.17 & 0.29 & -0.01 & -0.03 \\
NorESM1 & 155.78 & 17.83 & 26.09 & 0.33 & -0.001 & -0.01 \\
\hline
\end{tabular}

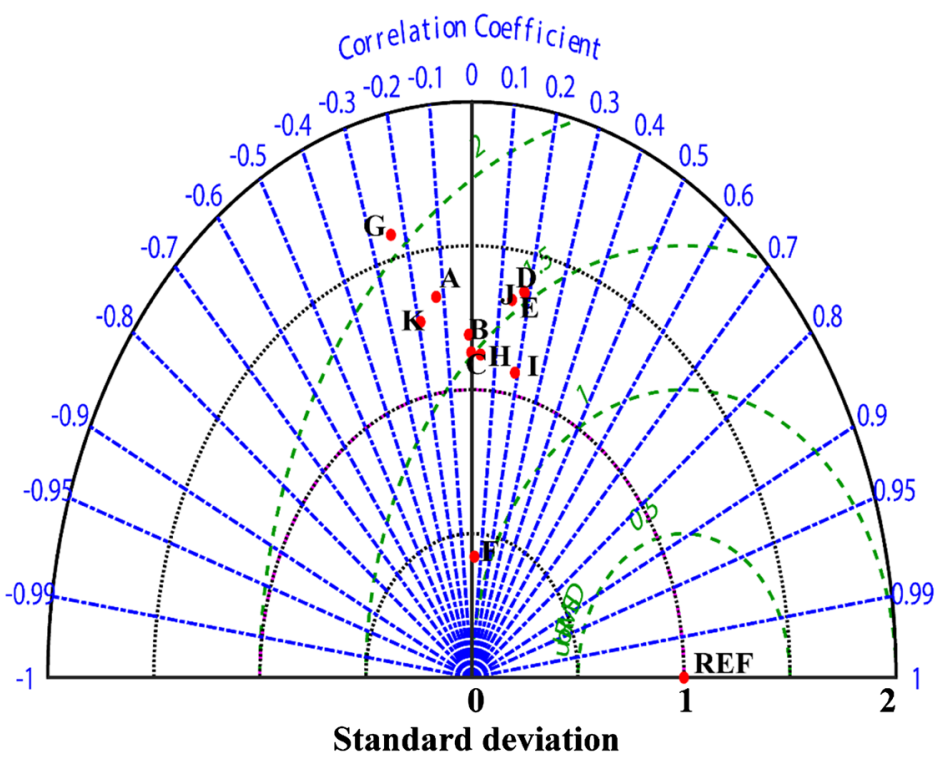

Figure 7. Summarized skills of RCA4 models in simulating observed SOND rains over Rwanda. The alphabetical letters denote; A-CanESM2, B-IPSL, C-CNRM, D-CSIRO, E-EC-Earth, F-Ensemble model, G-HadGEM2, H-GFDL-ESM2M, I-MIROC5, J-MPI, K-NorESM1.

the observed SOND rain characteristics.

\subsection{Annual Scale Characteristics}

At the annual mean time scale, the ability of the RCA4 climate models to simulate the mean annual statistics are illustrated in the Table 4. The results show that, all the models with exception of EC-Earth exhibit dry bias. The RMSE results show that the models exhibit bias in terms of the spatial distribution of mean rainfall to various extent. The observed annual rainfall over Rwanda shows 
Table 4. The skills of RCA4 models in simulating total annual rainfall ( $\mathrm{mm} / \mathrm{year}$ ) over Rwanda.

\begin{tabular}{ccccccc}
\hline Model & Mean & \%Bias & Stdev & RMSE & MK & TSA \\
\hline OBS & 1310.58 & & 104.7 & & -0.02 & -0.21 \\
CanESM2 & 1166.52 & -10.99 & 130.76 & 0.17 & 0.00 & 0.00 \\
IPSL & 1217.72 & -7.09 & 133.93 & 0.15 & 0.01 & 0.21 \\
CNRM & 1093.96 & -16.53 & 150.11 & 0.21 & -0.17 & -2.45 \\
CSIRO & 1169.50 & -10.76 & 136.27 & 0.18 & -0.04 & -0.68 \\
EC-Earth & 1379.91 & 5.29 & 129.27 & 0.14 & -0.03 & -0.34 \\
ENS & 1144.12 & -12.70 & 42.34 & 0.15 & 0.03 & 0.13 \\
GFDL & 1165.40 & -11.08 & 162.15 & 0.19 & 0.02 & 0.32 \\
HadGEM2 & 784.89 & -40.11 & 122.40 & 0.42 & 0.06 & 0.72 \\
MIROC5 & 1168.61 & -10.83 & 149.28 & 0.17 & 0.19 & 2.88 \\
MPI & 1221.15 & -6.82 & 147.77 & 0.15 & 0.07 & 1.01 \\
NorESM1 & 1073.51 & -18.09 & 125.31 & 0.23 & 0.13 & 1.62 \\
\hline
\end{tabular}

a decreasing trend at a rate of $-0.02 \mathrm{~mm} /$ year. The three RCA4 models (CNRM, CSIRO, and EC-Earth) are able to capture this decreasing trend, as shown in Table 4).

Notably, the inadequacy of RCA4 models to capture the correct sign of trend is consistent with the finding that was documented by previous studies which also focused on this region [18] [59] [60]. Such bias may be traced back to the driving GCMs models that have been dynamically downscaled. It is worth mentioning that the RCA4 models that are driven by ERA-Interim dataset skillfully simulate rainfall trends compared to those driven by CMIP data [61].

The summary of the skills of RCA4 climate models in simulating the observed annual rainfall is shown using a Taylor diagram in Figure 8. The results show that there is little agreement between the models in capturing the statistical aspects of the annual rainfall over Rwanda.

The RCA4 models exhibits some biases in simulating the annual mean rainfall to various extent. Clearly, the multi-model ensemble result performs better than the individual models in this category.

\subsection{Summarizing the Skills of RCA4 Models Using Skill Score}

The models were gauged on their capability to simulated seasonal and annual rainfall over Rwanda. The models portrayed mixed performance in simulating rainfall at all scales (Figure 9). Notably, individual models perform differently at a different scale. The RCA4 models show reasonable skills in simulating SOND seasonal rainfall than both MAM and annual rainfall. These findings are coherent with previous studies over the region that deployed different GCMs models [13] [14] [15] [18]. Remarkably, the ensemble model outperforms the skills of the individual model in simulating the observed rainfall features over Rwanda. 


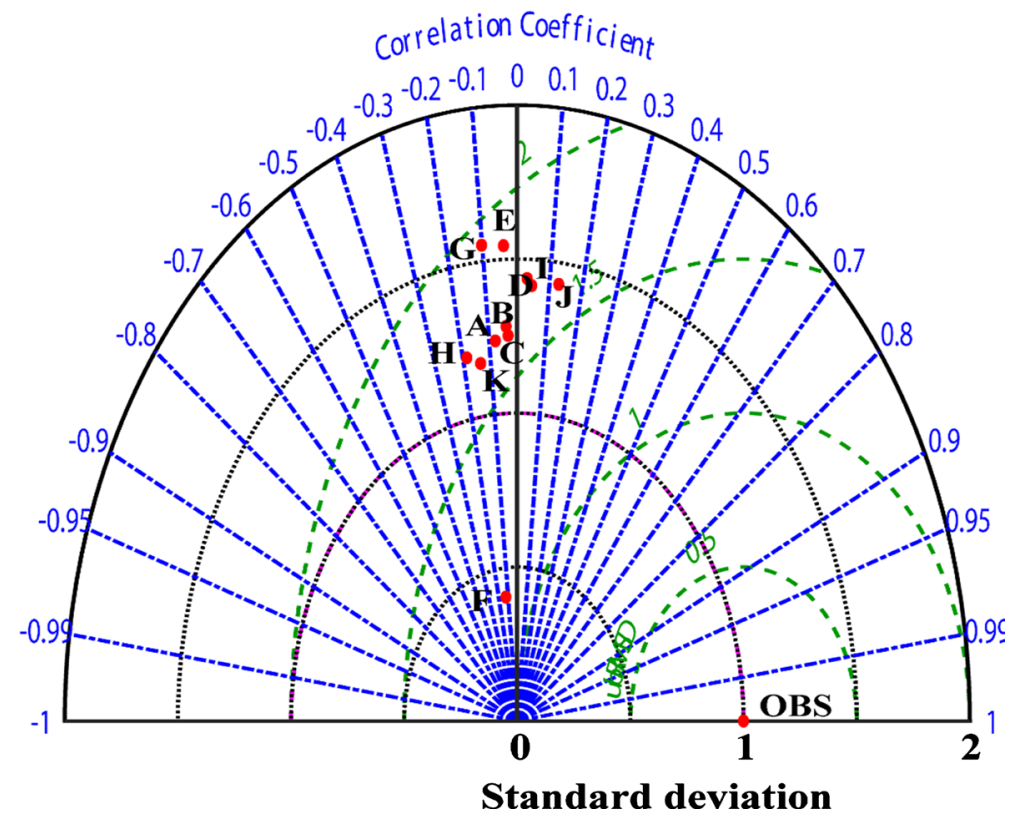

Figure 8. Pictorial depiction of RCA4 models in simulating total annual rainfall. The alphabetical letters denote; A-CanESM2, B-IPSL, C-CNRM, D-CSIRO, E-EC-Earth, F-Ensemble model, G-GFDL-ESM2M, H-HadGEM2, I-MIROC5, J-MPI, K-NorESM1.

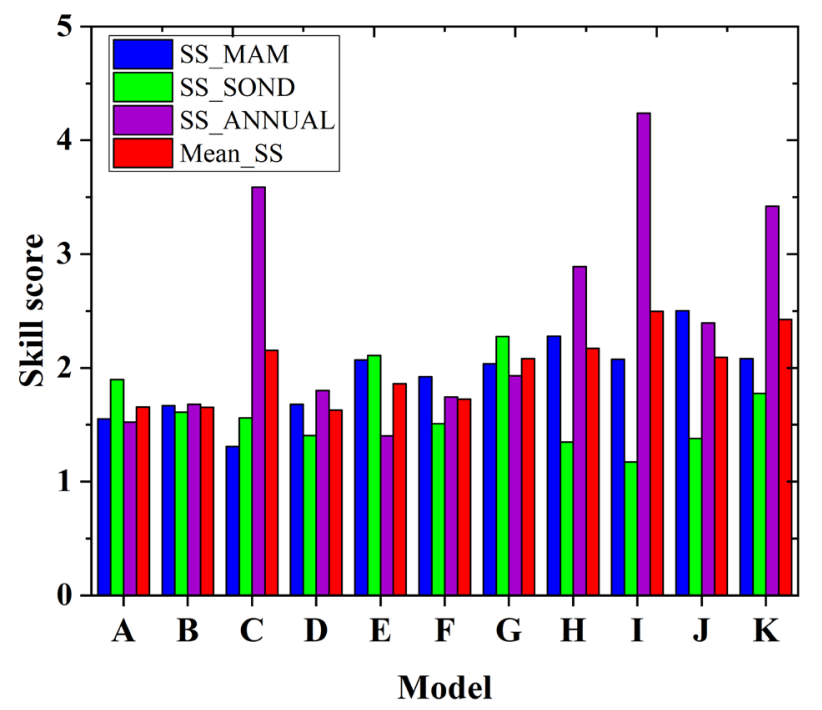

Figure 9. Skill score of the RCA4 historical models in simulating seasonal and annual rainfall over Rwanda. The alphabetical letters denote; A-CanESM2, B-IPSL, C-CNRM, D-CSIRO, E-EC-Earth, F-Ensemble model, G-GFDL-ESM2M, H-HadGEM2, I-MIROC5, J-MPI, K-NorESM1.

The best model in simulating observed MAM seasonal rainfall is CNRM while the least performing model is MPI. During SOND rainy season, MIROC5 outperforms all other models including the ensemble model which is number six out of eleven. The least skilled model in this category is GFDL. At the annual scale, EC-Earth shows more reasonable skills in simulating observed annual rainfall characteristics while MIROC5 was the least skilled. This mixed performance portrays that, no individual model performs skillfully at all time scale. 
Therefore, model selection should be based on the intended use of the model. This calls for improvement of model parametrization to capture the large-scale factors (ENSO and IOD) and mesospheric factors (Complex topography and significant water bodies) that modulate rainfall over the study domain and the greater East Africa.

Ranking the overall performance of the models is crucial as it acts as a basis for model selection to be used for future climate projection. Therefore, the models can be ranked from the best performing model to the least as; CSIRO, CanESM2, CNRM, GFDL, MIROC5, ENS, EC-Earth, HadGEM2, IPSL, MPI, and NorESM1.

\section{Conclusion and Recommendations.}

The present study aims at ranking the performance of ten RCA4 historical models that were driven by CMIP5 climate models against the observed gridded datasets as obtained from GPCC from 1951-2005 over Rwanda. The study deployed both statistical metrics and geospatial methods to understand both spatial and temporal skills of the RCA4 models in simulating the observed seasonal and annual rainfall characteristics. For consistency purposes and fair comparison, all the models and the GPCC dataset were regridded to a common resolution of $0.5^{\circ} \times 0.5^{\circ}$ using bilinear interpolation. The results show that Rwanda receives a bimodal rainfall regime; March-May (MAM) and September-December (SOND). The historical RCA4 climate models are inconsistent in simulating this annual cycle with most of the models showing wet bias and three of them exhibiting dry bias during MAM rainy season. However, the historical RCA4 models are coherent in simulating the SOND seasonal rainfall although they exhibit a wet bias.

The RCA4 historical models are skillfully in simulating the mean annual cycle than capturing the temporal pattern at both seasonal and annual scale. Most of the models exhibited inadequate skills in simulating rainfall trends and magnitude. This signifies the inadequacy of the GCMs models even after downscaling to simulate the mechanisms that modulated interannual variability of rainfall over the region. The performance of the RCA4 historical models differs from one-time scale to another with huge bias. The historical models can be ranked from the best performing model to the least as; CSIRO, CanESM2, CNRM, GFDL, MIROC5, ENS, EC-Earth, HadGEM2, IPSL, MPI, and NorESM1. The ensemble model outperforms some individual models in capturing the mean statistics of rainfall over Rwanda.

The findings of this study are meaningful to both policymakers and climate modelers. The modeler can use the results to improve on the models' parametrization schemes and physics in order to reduce the chronic bias documented. We highly recommend deployment of bias correction techniques on RCA4 future climate models before using them for future rainfall projections and impact studies. Additionally, the selection of the model should be based on the purpose of the study due to mixed performance of the models at different time scale. 


\section{Acknowledgements}

This work was jointly supported by the National Key Research and Development Program of China [grant number 2019YFC1510004], NSFC Grants (No. 42005020) and the National Key Research and Development Program on Monitoring, Early Warning and Prevention of Major Natural Disaster (2018YFC1506002). Additionally, special thanks to RCA4 group for downscaling the CMIP5 data and ESG for openly availing the data. We are also grateful to Rwanda Meteorology Agency for the provision of the observation data. The authors are grateful to Nanjing University of Information Science and Technology (NUIST), China for creating an enabling environment to carry out research globally. We are highly indebted to the editor for contacting three anonymous reviewers to complete the review in time and we thank the experts in the field who helped improve the work to the current state.

\section{Conflicts of Interest}

The authors declare no conflicts of interest regarding the publication of this paper.

\section{References}

[1] Anyah, R.O. and Qiu, W. (2012) Characteristic 20th and 21st Century Precipitation and Temperature Patterns and Changes over the Greater Horn of Africa. International Journal of Climatology, 32, 347-363. https://doi.org/10.1002/joc.2270

[2] IPCC (2014) Climate Change: Synthesis Report. Contribution of Working Groups I, II and III to the Fifth Assessment Report of the Intergovernmental Panel on Climate Change [Core Writing Team, Pachauri, R.K. and Meyer, L.A. (eds.)]. IPCC, Geneva, Switzerland, 151.

[3] Alexander, L.V. and Arblaster, J.M. (2017) Historical and Projected Trends in Temperature and Precipitation Extremes in Australia in Observations and CMIP5. Weather and Climate Extremes, 15, 34-56. https://doi.org/10.1016/j.wace.2017.02.001

[4] World Bank (2012) Doing Business in the East African Economies. IFC/World Bank Rep, 116.

[5] Ilunga, L., Muhire, I. and Mbaragijimana, C. (2004) Pluviometric Seasons and Rainfall Origin in Rwanda. Geo-Eco-Trop, 28, 61-68.

[6] David, K., Megan, C., Christian, C., Jillian, D., Ryan, H., Robert, M., Mathew, W., Sally, T., Andrew, A.B. and Michael, H. (2011) Green Growth and Climate Resilience National Strategy for Climate Change and Low Carbon Development. Republic of Rwanda, Kigali.

[7] Muhire, I. and Ahmed, F. (2014) Spatio-Temporal Trend Analysis of Precipitation Data over Rwanda. South African Geographical Journal, 97, 50-68. https://doi.org/10.1080/03736245.2014.924869

[8] Ngarukiyimana, J.P., Fu, Y., Yang, Y., Ogwang, B.A., Ongoma, V. and Ntwali, D. (2018) Dominant Atmospheric Circulation Patterns Associated with Abnormal Rainfall Events over Rwanda, East Africa. International Journal of Climatology, 38, 187 202. https://doi.org/10.1002/joc.5169

[9] Ntirenganya, F. (2018) Analysis of Rainfall Variability in Rwanda for Small-Scale Farmers Coping Strategies to Climate Variability. East African Journal of Science 
and Technology, 8, 75-96.

[10] Asumadu-Sarkodie, S., Rufangura, P., Jayaweera, M.P.C. and Owusu, P.A. (2015) Situational Analysis of Flood and Drought in Rwanda. International Journal of Scientific and Engineering Research, 6, 960-970. https://doi.org/10.14299/ijser.2015.08.013

[11] Ayugi, B., Tan, G., Gnitou, G.T., Ojara, M. and Ongoma, V. (2019) Historical Evaluations and Simulations of Precipitation over East Africa from Rossby Centre Regional Climate Model. Atmospheric Research, 232, Article ID: 104705. https://doi.org/10.1016/j.atmosres.2019.104705

[12] Bhattacharjee, P.S. and Zaitchik, B.F. (2015) Perspectives on CMIP5 Model Performance in the Nile River Headwaters Regions. International Journal of Climatology, 35, 4262-4275. https://doi.org/10.1002/joc.4284

[13] Ongoma, V., Chen, H. and Gao, C. (2018) Evaluation of CMIP5 Twentieth Century Rainfall Simulation over the Equatorial East Africa. Theoretical and Applied Climatology, 135, 893-910. https://doi.org/10.1007/s00704-018-2392-x

[14] Kisembe, J., Favre, A., Alessandro, D., Lennard, C., Sabiiti, G. and Nimusiima, A. (2019) Evaluation of Rainfall Simulations over Uganda in CORDEX Regional Climate Models. Theoretical and Applied Climatology, 137, 1117-1134. https://doi.org/10.1007/s00704-018-2643-x

[15] Mumo, L. and Yu, J. (2020) Gauging the Performance of CMIP5 Historical Simulation in Reproducing Observed Gauge Rainfall over Kenya. Atmospheric Research, 236, Article ID: 104808. https://doi.org/10.1016/j.atmosres.2019.104808

[16] Müller, C., Waha, K., Bondeau, A. and Heinke, J. (2014) Hotspots of Climate Change Impacts in Sub-Saharan Africa and Implications for Adaptation and Development. Global Change Biology, 20, 2505-2517. https://doi.org/10.1111/gcb.12586

[17] Raghavan, S.V., Liu, J., Nguyen, N.S., Vu, M.T. and Liong, S.-Y. (2018) Assessment of CMIP5 Historical Simulations of Rainfall over Southeast Asia. Theoretical and Applied Climatology, 132, 989-1002. https://doi.org/10.1007/s00704-017-2111-Z

[18] Ayugi, B., Tan, G., Gnitou, G.T., Ojara, M. and Ongoma, V. (2019) Historical Evaluations and Simulations of Precipitation over East Africa from Rossby Centre Regional Climate Model. Atmospheric Research, 232, Article ID: 104705. https://doi.org/10.1016/j.atmosres.2019.104705

[19] Stensrud, D.J. (2009) Parameterization Schemes: Keys to Understanding Numerical Weather Prediction Models. Cambridge University Press, Cambridge.

[20] Meehl, G.A., Boer, G.J., Covey, C., Latif, M. and Stouffer, R.J. (2000) The Coupled Model Intercomparison Project (CMIP). Bulletin of the American Meteorological Society, 81, 313-318. https://doi.org/10.1175/1520-0477(2000)081<0313:TCMIPC>2.3.CO;2

[21] Taylor, K., Stouffer, R. and Meehl, G. (2012) An Overview of CMIP5 and the Experiment Design. Bulletin of the American Meteorological Society, 93, 485-498. https://doi.org/10.1175/BAMS-D-11-00094.1

[22] Otieno, V.O. and Anyah, R.O. (2013) CMIP5 Simulated Climate Conditions of the Greater Horn of Africa (GHA) Part 1: Contemporary Climate. Climate Dynamics, 41, 2081-2097. https://doi.org/10.1007/s00382-012-1549-Z

[23] Wilby, R.L., Dawson, C.W. and Barrow, E.M. (2002) SDSM-A Decision Support Tool for the Assessment of Regional Climate Change Impacts. Environmental Modelling \& Software, 17, 145-157. https://doi.org/10.1016/S1364-8152(01)00060-3 
[24] Favre, A., Philippon, N., Pohl, B., Kalognomou, E.-A., Lennard, C., Hewitson, B., Cerezo-Mota, R., et al. (2016) Spatial Distribution of Rainfall Annual Cycles over South Africa in 10 CORDEX Regional Climate Model Present-Day Simulations. Climate Dynamics, 46, 1799-1818. https://doi.org/10.1007/s00382-015-2677-z

[25] Zhao, M., Held, I.M., Lin, S.-J. and Vecchi, G.A. (2009) Simulations of Global Hurricane Climatology, Interannual Variability, and Response to Global Warming Using a 50-km Resolution GCM. Journal of Climate, 22, 6653-6678. https://doi.org/10.1175/2009JCLI3049.1

[26] Gent, P.R., Yeager, S.G., Neale, R.B., Levis, S. and Bailey, D.A. (2010) Improvements in a Half Degree Atmosphere/Land Version of the CCSM. Climate Dynamics, 34, 819-833. https://doi.org/10.1007/s00382-009-0614-8

[27] Laprise, R., Kornic, D., Rapaic, M., Separovic, L., LeDuc, M., Nikiema, O., Di Luca, A., Diaconescu, E., Alexandru, A., Lucas-Picher, P., et al. (2020) Considerations of Domain Size and Large-Scale Driving for Nested Regional Climate Models: Impact on Internal Variability and Ability at Developing Small-Scale Details. Springer, Berlin/Heidelberg, 181-199. https://doi.org/10.1007/978-3-7091-0973-1_14

[28] Gusain, A., Ghosh, S. and Karmakar, S. (2020) Added Value of CMIP6 over CMIP5 Models in Simulating Indian Summer Monsoon Rainfall. Atmospheric Research, 232, Article ID: 104680. https://doi.org/10.1016/j.atmosres.2019.104680

[29] Endris, H.S., Lennard, C., Hewitson, B., Dosio, A., Nikulin, G. and Panitz, H.-J. (2016) Teleconnection Responses in Multi-GCM Driven CORDEX RCMs over Eastern Africa. Climate Dynamics, 46, 2821-2846. https://doi.org/10.1007/s00382-015-2734-7

[30] Dee, D.P., Uppala, S.M., Simmons, A.J., Berrisford, P., Poli, P., Kobayashi, S., Andrae, U., Balmaseda, M.A., Balsamo, G., Bauer, P., Bechtold, P., Beljaars, A.C.M., van de Berg, L., Bidlot, J., Bormann, N., Delsol, C., Dragani, R., Fuentes, M., Geer, A.J., Haimberger, L., Healy, S.B., Hersbach, H., Hólm, E.V., Isaksen, L., Kållberg, P., Köhler, M., Matricardi, M., McNally, A.P., Monge-Sanz, B.M., Morcrette, J.-J., Park, B.-K., Peubey, C., de Rosnay, P., Tavolato, C., Thépaut, J.-N. and Vitart, F. (2011) The ERA-Interim Reanalysis: Configuration and Performance of the Data Assimilation System. Quarterly Journal of the Royal Meteorological Society, 137, 553-597. https://doi.org/10.1002/qj.828

[31] Akinsanola, A.A., Ajayi, V.O., Adejare, A.T., Adeyeri, O.E., Gbode, I.E., Ogunjobi, K.O., Nikulin, G. and Abolude, A.T. (2017) Evaluation of Rainfall Simulations over West Africa.

[32] Muhire, I., Ahmed, F. and Abutaleb, K. (2015) Relationships between Rwandan Seasonal Rainfall Anomalies and ENSO Events. Theoretical and Applied Climatology, 122, 271-284. https://doi.org/10.1007/s00704-014-1299-4

[33] Jonah, K., Wen, W., Shahid, S., Ali, M.A., Bilal, M., Habtemicheal, B.A., Tiwari, P., et al. (2021) Spatiotemporal Variability of Rainfall Trends and Influencing Factors in Rwanda. Journal of Atmospheric and Solar-Terrestrial Physics, 219, Article ID: 105631. https://doi.org/10.1016/j.jastp.2021.105631

[34] Black, E., Slingo, J.M. and Sperber, K.R. (2003) An Observational Study of the Relationship between Excessively Strong Short Rains in Coastal East Africa and Indian Ocean SST. Monthly Weather Review, 131, 74-94. https://doi.org/10.1175/1520-0493(2003)131<0074:AOSOTR>2.0.CO;2

[35] Nicholson, S.E. and Grist, J.P. (2003) The Seasonal Evolution of the Atmospheric Circulation over West Africa and Equatorial Africa. Journal of Climate, 16, 1013 1030. https://doi.org/10.1175/1520-0442(2003)016<1013:TSEOTA $>2.0 . C O ; 2$

[36] Washington, R. and Preston, A. (2006) Extreme Wet Years over Southern Africa: 
Role of Indian Ocean Sea-Surface Temperatures. Journal of Geophysical Research, 111, D15104. https://doi.org/10.1029/2005JD006724

[37] Kizza, M., Rodhe, A., Xu, C.-Y., Ntale, H.K. and Halldin, S. (2009) Temporal Rainfall Variability in the Lake Victoria Basin in East Africa during the Twentieth Century. Theoretical and Applied Climatology, 98, 119-135. https://doi.org/10.1007/s00704-008-0093-6

[38] Shongwe, M.E., van Oldenborgh, G.J., van den Hurk, B. and van Aalst, M. (2011) Projected Changes in Mean and Extreme Precipitation in Africa under Global Warming. Part II: East Africa. Journal of Climate, 24, 3718-3733. https://doi.org/10.1175/2010JCLI2883.1

[39] Endris, H.S., Omondi, P., Jain, S., Lennard, C., Hewitson, B., Chang'a, L., Awange, J.L., Dosio, A., Ketiem, P., Nikulin, G., Panitz, H.J., Büchner, M., Stordal, F., Tazalika, L., Al, E.E.T., Anitz, R.P. and Atthias, M.B.U. (2013) Assessment of the Performance of CORDEX Regional Climate Models in Simulating East Africa Rainfall. Journal of Climate, 26, 8453-8475. https://doi.org/10.1175/JCLI-D-12-00708.1

[40] Manatsa, D., Morioka, Y., Behera, S.K., Matarira, C.H. and Yamagata, T. (2014) Impact of Mascarene High Variability on the East African "Short Rains". Climate Dynamics, 42, 1259-1274. https://doi.org/10.1007/s00382-013-1848-Z

[41] Ogwang, B.A., Chen, H., Tan, G., Ongoma, V. and Ntwali, D. (2015) Diagnosis of East Africa Climate and the Circulation Mechanisms Associated with Extreme Wet and Dry Events: A Study Based on RegCM4. Arabian Journal of Geosciences, 8, 10255-10265. https://doi.org/10.1007/s12517-015-1949-6

[42] Behera, S.K., Luo, J.-J., Masson, S., Delecluse, P., Gualdi, S., Navarra, A. and Yamagata, T. (2005) Paramount Impact of the Indian Ocean Dipole on the East Africa Short Rains: A CGCM Study. Journal of Climate, 18, 4514-4530.

https://doi.org/10.1175/JCLI3541.1

[43] Unden, P., Rontu, L., Jinen, H., Lynch, P., Calvo, J., Cats, G., Cuxart, J., Eerola, K., Fortelius, C., Garcia-Moya, J.A., Jones, C., Geert Lenderlink, G., Mcdonald, A., Mcgrath, R., Navascues, B., Nielsen, N.W., Degaard, V., Rodriguez, E., Rummukainen, M., Sattler, K., Sass, B.H., Savijarvi, H., Schreur, B.W. and Sigg, R. (2002) HIRLAM-5 Scientific Documentation.

https://repositorio.aemet.es/bitstream/20.500.11765/6323/1/HIRLAMSciDoc Dec20 02.pdf

[44] Tamoffo, A.T., Moufouma-Okia, W., Dosio, A., James, R., Pokam, W.M., Vondou, D.A. and Nouayou, R. (2019) Process-Oriented Assessment of RCA4 Regional Climate Model 44 Projections over the Congo Basin under $1.5{ }^{\circ} \mathrm{C}$ and $2{ }^{\circ} \mathrm{C}$ Global Warming Levels: Influence of Regional Moisture Fluxes. Climate Dynamics, 53, 1911-1935.

[45] Samuelsson, P., Jones, C.G., Willén, U., Ullerstig, A., Gollvik, S., Hansson, U., Hansson, U., Jansson, C., Kjellströ, E., Nikulin, G. and Wyser, K. (2012) The Rossby Centre Regional Climate Model RCA3: Model Description and Performance. Tellus $A, 63,4-23$. https://doi.org/10.1111/j.1600-0870.2010.00478.x

[46] Casanova, S. and Ahrens, B. (2009) On the Weighting of Multimodel Ensembles in Seasonal and Short-Range Weather Forecasting. Monthly Weather Review, 137, 3811-3822. https://doi.org/10.1175/2009MWR2893.1

[47] Mann, H.B. (1945) Nonparametric Tests against Trend. Econometrica, 13, 245-259. https://doi.org/10.2307/1907187

[48] Kendall, M. (1975) Rank Correlation Methods. 4th Edition, Charles Griffin, San Francisco, 8. 
[49] Sen, P.K. (1968) Estimates of the Regression Coefficient Based on Kendall's Tau. Journal of the American Statistical Association, 63, 1379-1389. https://doi.org/10.1080/01621459.1968.10480934

[50] Xu, M., Kang, S., Wu, H. and Yuan, X. (2018) Detection of Spatio-Temporal Variability of Air Temperature and Precipitation Based on Long-Term Meteorological Station Observations over Tianshan Mountains, Central Asia. Atmospheric Research, 203, 141-163. https://doi.org/10.1016/j.atmosres.2017.12.007

[51] Ongoma, V. and Chen, H. (2017) Temporal and Spatial Variability of Temperature and Precipitation over East Africa from 1951 to 2010. Meteorology and Atmospheric Physics, 129, 131-144. https://doi.org/10.1007/s00703-016-0462-0

[52] Mumo, L., Yu, J. and Ayugi, B. (2019) Evaluation of Spatiotemporal Variability of Rainfall over Kenya from 1979 to 2017. Journal of Atmospheric and Solar-Terrestrial Physics, 194, Article ID: 105097.

https://doi.org/10.1016/j.jastp.2019.105097

[53] Tadeyo, E., Chen, D., Ayugi, B. and Yao, C. (2020) Characterization of Spatio-Temporal Trends and Periodicity of Precipitation over Malawi during 19792015. Atmosphere, 11, 891. https://doi.org/10.3390/atmos11090891

[54] Tan, G., Ayugi, B., Ngoma, H. and Ongoma, V. (2020) Projections of Future Meteorological Drought Events under Representative Concentration Pathways (RCPs) of CMIP5 over Kenya, East Africa. Atmospheric Research, 246, Article ID: 105112. https://doi.org/10.1016/j.atmosres.2020.105112

[55] Taylor, K.E. (2001) Summarizing Multiple Aspects of Model Performance in a Single Diagram. Journal of Geophysical Research: Atmospheres, 106, 7183-7192. https://doi.org/10.1029/2000JD900719

[56] Fu, G., Liu, Z., Charles, S.P., Xu, Z. and Yao, Z. (2013) A Score-Based Method for Assessing the Performance of GCMs: A Case Study of Southeastern Australia. Journal of Geophysical Research: Atmospheres, 118, 4154-4167. https://doi.org/10.1002/jgrd.50269

[57] Yang, W., Seager, R., Cane, M.A. and Lyon, B. (2015) The Rainfall Annual Cycle Bias over East Africa in CMIP5 Coupled Climate Models. Journal of Climate, 28, 9789-9802. https://doi.org/10.1175/JCLI-D-15-0323.1

[58] Rowell, D.P., Booth, B.B., Nicholson, S.E. and Good, P. (2015) Reconciling Past and Future Rainfall Trends over East Africa. Journal of Climate, 28, 9768-9788. https://doi.org/10.1175//CLI-D-15-0140.1

[59] Endris, H.S., Omondi, P., Jain, S., Lennard, C., Hewitson, B., Chang'a, L., Awange, J.L., Dosio, A., Ketiem, P., Nikulin, G., Panitz, H.J., Büchner, M., Stordal, F., Tazalika, L., Al, E.E.T., Anitz, R.P. and Atthias, M.B.U. (2013) Assessment of the Performance of CORDEX Regional Climate Models in Simulating East African Rainfall. Journal of Climate, 26, 8453-8475. https://doi.org/10.1175/JCLI-D-12-00708.1

[60] Luhunga, P., Botai, J. and Kahimba, F. (2016) Evaluation of the Performance of CORDEX Regional Climate Models in Simulating Present Climate Conditions of Tanzania. Journal of Southern Hemisphere Earth Systems Science, 66, 32-54. https://doi.org/10.1071/ES16005

[61] Mutayoba, E. and Kashaigili, J.J. (2017) Evaluation for the Performance of the CORDEX Regional Climate Models in Simulating Rainfall Characteristics over Mbarali River Catchment in the Rufiji Basin. Tanzania. Journal of Geoscience and Environment Protection, 5, 139-151. https://doi.org/10.4236/gep.2017.54011 